\title{
Age Demographics and the Changing Face of Healthcare
}

\author{
Gerald Martone* \\ MS, MSN, PMHNP-BC, Alaska Psychiatric Institute, Anchorage, USA
}

Submission: August 17, 2018; Published: August 23, 2018

*Corresponding author: Gerald Martone,MS, MSN, PMHNP-BC, Alaska Psychiatric Institute, Anchorage, Alaska, USA, Tel: (907) 538-7801; Email: Gerald.Martone@alaska.gov

\section{Opinion}

The last couple of decades have witnessed a demographic shift from societies where people had many children and died young to societies that now have fewer children but live longer; from highfertility and high-mortality to low-fertility and low-mortality. Humans are living longer than they ever have. We're not having a 'population explosion'; we're having a 'health explosion.'Even hunger is decreasing as a contributing factor in global mortality. Malnutrition was a major factor leading to early death just twenty years ago. Now the main risk factor contributing to morbidity and mortality is obesity.One of the signature achievements in public health of the 20th century was the extension of the human life span. Over $12 \%$ of the world's population now is age 60 years and older.

This is not just a phenomenon of developed industrialized countries. Sixty percent of the world's older persons currently live in developing countries. By 2050, 80\% of the world's older persons will be living in developing countries. A lot has been said about the youth bulge in poorer parts of the world but many of these countries are just beginning to consider what the rapidly aging global demographic will mean for them.Right now is probably the last time in human history when the world will have more young people than elders. Starting in 2000 , there were more people over the age of 60 than children under five years old. As it turns out, children are not our future. The youth bulge is nearing its historical peak (although sub-Saharan Africa's youth bulge has a long tail that is expected to extend into the next decade or two). In the next ten years, older people will outnumber children for the first time in human history.Recently in rapidly aging Japan, the sale of adult diapers has exceeded baby diapers. The adult incontinence products industry is growing at several percent a year along with the needs of a rapidly growing elder population globally.

At this time one of the fastest growing demographics globally is people over the age of 60 . This is currently $12.5 \%$ of the world's population and represents over 860 million people. Older persons are also some of the most isolated, at-risk, and unprotected groups in society. It is much harder for them to seek assistance and ask for help.As of 2009, there were already 455,000 people in the world over 100 years old. By 2050, it is estimated that there will be over 2 million centenarians. Right now in the United States, there are 71,000 people over the age of 100 years old. In the U.S., every eight seconds someone turns 65 years old. That's more than 10,000 people per day. People over the age of 85 are the fastest growing segment of the American population. And dementia afflicts one in every two of them.

Alzheimer's disease is the $6^{\text {th }}$ leading cause of death in the United States. Providing care for patients with dementia is labor intensive and costly. The financial burden in the U.S. alone is higher than heart disease or cancer. As the numbers of people afflicted and the costs for their care double over the next 30 years, it will overwhelm the health care field.The demand for caregivers willing to take care of the aging population will ultimately change Americans' attitude toward immigration. There are even predictions of the future where healthcare recruiting companies will drive buses to the Mexican border to lure immigrant workers into the U.S.'s long-term care facilities. The countries with the lowest birthrates will need workers while the countries with the highest birthrates need work.Nearly half of the world's population lives in countries where the birthrates are below the replacement level. For some nations, they are simply not replacing their population. It might be that in the future young people will be an even scarcer resource. With rapidly aging populations and less young people entering the global workforce, some countries will face a new type of economic strain.

There are already as many as 60 countries in the world facing a critical shortage of health care workers. According to some estimates, the global health care workforce needs a minimum of five million additional persons with a greater range of skills just to meet current demands for global health. The crisis of an inadequate and insufficient health care workforce is one of the obstacles standing in the way of achieving development goals in many countries. The impending challenges of assisting a rapidly aging world population has been cynically referred to as the "gray tsunami". By 2050 there will be over two billion people over the 
age of 60 with the proportion of women growing most quickly. More than 100 million people globally will have Alzheimer's disease. If they were a country, they would be the 12th largest nation on earth.

In addition to physical frailty, complicated medical regimens, and mobility impairments, they are the least connected segment of the adult population. Most people communicate and exchange information through the Internet. Many seniors do not have the familiarity and fluency with digital technology to participate in that form of communication.In the United States, $70 \%$ of those who died in Hurricane Katrina in 2005 were over 60 years old. Half the deaths in the tornado in Joplin, Missouri were older adults. In the last count of deaths from Hurricane Sandy in the
East Coast, almost 40 percent were over the age of 60 . Most of them had drowned.

With our current focus on children and youth, very few agencies have begun to analyze the impact of increasingly elderly and aging populations on public health. Furthermore between 4 to 6 percent of older persons worldwide have suffered from some form of elder abuse; either physical abuse, emotional abuse, or financial abuse. Recent research suggests that abuse, neglect, and violence against older persons, both at home and in institutions, are much more prevalent than is acknowledged.

\section{Conclusion}

Are we prepared for this impending public health revolution? Is our healthcare workforce up to this challenge? 